\title{
Aylan Kurdi'den Sonra: Sanatta Göçün Kaydı
}

\author{
After Aylan Kurdi: Recording of Migration in Art \\ Önder Yağmur \\ Doç., Atatürk Üniversitesi, Güzel Sanatlar Fakültesi, Heykel Bölümü \\ email: oyagmur@atauni.edu.tr (DORCID ID: https://orcid.org/0000-0003-1022-0931
}

\section{İbrahim Arslan}

Arş. Gör., Atatürk Üniversitesi, Güzel Sanatlar Fakültesi, Heykel Bölümü

email: arslanibrahim@atauni.edu.tr (DORCID ID: https://orcid.org/0000-0001-5146-3863

\begin{abstract}
$\checkmark$ iThenticate' $\mathrm{Bu}$ makale bilimsel etik ve kurallara uygun hazırlanmış ve intihal incelemesinchers gerektirmemektedir.
\end{abstract}

Atıf (APA 6)/To cite this article

Yağmur, Ö., \& Arslan, İ. (2021). Aylan Kurdi'den sonra: Sanatta göçün kayd1. Atatürk Üniversitesi Güzel Sanatlar Enstitüsü Dergisi, 27(46), 249-257. https://doi.org/10.35247/ataunigsed.841876

Makale Gönderim Tarihi/Received: 16/12/2020

Makale Kabul Tarihi/Accepted: 31/01/2021

Makale Yayın Tarihi/Published: 30/03/202

Review Article/Derleme Makale

$\ddot{O} z$

Binlerce y1l öncesinde yaşam biçimi olan göçebelik, bireylerin ve toplumların hayatını şekillendiren bir fiil olarak karşımıza çıkmaktadır. Neolitik devrimle yerleşik düzene geçen insanoğlu temel barınma ve beslenme ihtiyaçlarını karșılayabildiği alanlarda hayatlarına devam etmiştir; ancak göç hareketleri son bulmamış ve çağlar boyunca kültürlerarası etkileşime katkı yapmaya devam etmiştir. Tercih sonucu ya da zorunlu bir fiil olan göç; bireysel ve toplumsal düzeyde birçok farklı etki yarattığı gibi sanat alanında da birtakım yansımalar ve etkiler ile karşımıza çıkmaktadır. Göç ve göçmenlik kavramları üzerinden kişisel fikirlerini farklı disiplinler aracılığı ile izleyiciye aktaran sanatçılar, kendi deneyimlerini ya da göç ile sonuçlanmış savaşlar, afetler, açlık gibi toplum belleğinde yer edinmiş birçok olay veya durumu ele alarak incelemiștir. Sinema, edebiyat ve tiyatro gibi çeșitli alanlarda nesne edinilen göç; plastik sanatlar alanında da sıklıkla kullanılmaktadır. Dünya toplumu birçok göç hareketine ve buna bağlı olarak birçok trajediye şahitlik etmiştir ancak; yaşanan bazı olaylar büyük çapta etkiler yaratmıştır. Aylan Kurdi ve ailesinin 2015 yılında çıktığı göç yolunda trajik biçimde hayatlarını kaybetmesi de yakın zamanda yaşanan büyük trajedilerden biridir ve bu çalıșmada Aylan Kurdi üzerinden işlenerek, göc teması etrafinda şekillenen sanat eserleri incelenmiş, yaşanan olayın plastik sanatlara yansımaları Ai Weiwei, Banksy, Pekka Jylhä gibi seçilmiș sanatçıların yapıtları özelinde değerlendirilmiștir.

Anahtar kelimeler: Plastik Sanatlar, Aylan Kurdi, Göç, Göçmen, Sanatsal Söylem

\begin{abstract}
Nomadism, a way of life thousands of years ago, has emerged as an act that shapes the lives of individuals and societies. Having settled down with the Neolithic revolution, human beings continued their lives in areas where they could meet their basic shelter and nutritional needs; however, migration movements have not ceased and have continued to contribute to intercultural interaction throughout the ages. Immigration, as a result of choice or an obligatory act, creates many different effects on individual and social levels and it also appears with some reflections and effects in the field of art. The artists, who convey their ideas to the audience through different disciplines over the concepts of immigration, have examined their own experiences or many events or situations that have taken place in the memory of society such as wars, disasters, the hunger that resulted in migration. Migration, which is an object of various fields such as cinema, literature, and theater, is also frequently used in the field of plastic arts. The world community has witnessed many migration movements and related tragedies. Some events that took place had a massive impact. The tragic loss of Aylan Kurdi and her family on their migration route in 2015 is one of the major tragedies recently. In this study, the artworks shaped around the migration theme were examined through Aylan Kurdi, and the reflections of the event on plastic arts were evaluated through the works of the artists such as Ai Weiwei, Banksy, Pekka Jylhä.
\end{abstract}

Keywords: Plastic Arts, Aylan Kurdi, Migration, Emigrant, Artistic Discourse

\section{Giriş}

İnsanoğlunun yerleşik hayata geçmeden önce rutini olan göç, yerleşik düzene geçtikten sonra bilinçli ya da zorunlu bir fiil haline gelmiştir. Gönüllü, zorunlu, iç, dış gibi birçok çeşidi olan; bireysel ya da topluca bir yerden veya yurttan bir diğerine hareket etme, taşınma durumuna göç denilmektedir (Türk Dil Kurumu, 1998). Tarih boyunca karşılaştığımız büyük ölçekli göç hareketleri bulunmaktır ve geniş çaplı insan hareketliliklerinin temelinde genellikle savaşlar ve mübadeleler yatmaktadır. M.S. 4. yüzyılda Çin devletinin baskılarından kurtulmak için batıya doğru hareket eden Hunlar ulaştıkları toprakların sakinleri olan çoğunluğu Cermen kavimlerden oluşan toplulukları göç etmeye zorlamışlardır. 19. yy. ortalarında yaşanan büyük Çerkez sürgünü, I. Dünya Savaşı sonrasında balkan ülkeleri ile yapılan mübadele Anadolu topraklarını da etkileyen göç hareketlerindendir. 1947 yılında Pakistan'ın egemenliğini kazanması sonucunda Hindistan ile yapılan mübadele sonrasında yaklaşık 18 milyon kişinin göç etmesi ve II. Dünya Savaşından kaynaklanan yaklaşık 40 milyon kişinin göç etmek zorunda kalması bilinen büyük insan hareketlilikleri arasındadır (Kınık, 2012).

Göç hareketleri hem yer değiştiren hem de varılan yerdeki toplum için birçok alanda değişikliği zaruri kılmaktadır. Özellikle uluslararası göçler bir takım uyum sorunları ile birlikte zaman zaman ülkelerin siyasi, ekonomik ve toplumsal dengelerini değişikliğe uğratmaktadır (Aksoy, 2012). Varılan yere, terkedilen yerden yalnızca bireyler 
değil; inançlar, gelenekler, alışkanlıklar, edinilmiş tüm deneyim ve bilgi birikimleri de götürülmektedir. İsviçreli yazar Max Frisch 20. yüzyılın sonlarında ülkemizden Almanya'ya yapılan iş̧̧i göçlerini "işçi istedik, insanlar geldi" cümlesiyle özetlemiştir ve göçün salt işgücü ile kısıtlı olmayıp sosyal göçe dönüştüğünü, kadın ve çocukların da dâhil olmasıyla kitlesel bir hal aldığını belirtmiştir (Adıgüzel, 2016). Göç, bir yandan birbirine yabancı iki farklı topluluğun bir arada yaşama zaruretini doğururken; diğer yandan iki farklı yaşam biçiminin sentez sonuçlarını da yaratmaktadır. Kültürlerarası (Yedikardeş, 2020, s. 23) zorunlu iletişimin neden olduğu bu değişiklikler sanat eserlerini de etkilemektedir. Ekonomik, siyasi, toplumsal ya da bireysel sebeplerden kaynaklanan bu eylem, sanatın her alanında irdelenmiş; birç̧ok farklı çalışmada izleyici ile "göçmen ya da göçmenlik kavramı" arasında bağ kurmak üzere kullanılmıştır. Örneğin siyahi sanaţ̧ı Jacop Lawrance, 1941 yılında yaptığı "Büyük Göç" (Görsel 1) adlı serisindeki 60 adet resimle, Amerika kıtasına götürülen siyahilerin "öteki olmak" hissini tuvale yansıtmıştır (Çalışkan, 2018).

\section{Görsel 1}

One-Way Ticket: Jacob Lawrence's Migration Series

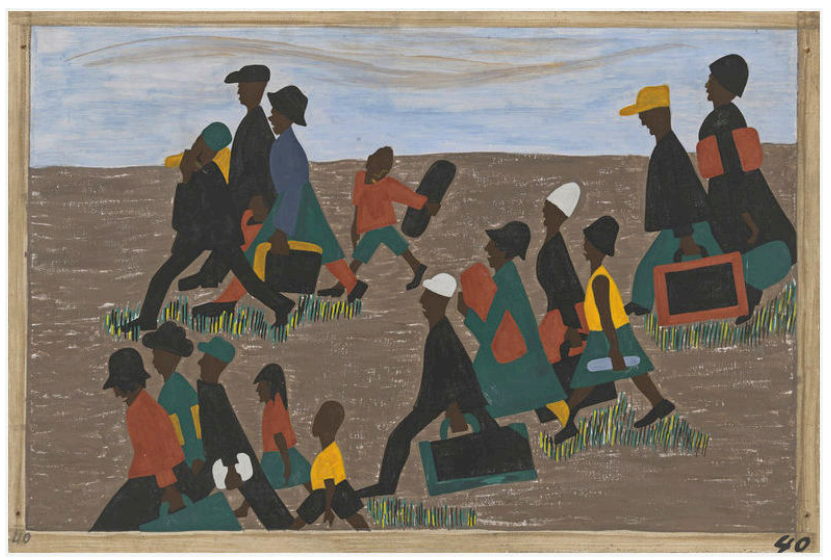

(Lawrence, 1941).

\section{Yöntem}

Araştırma Betimsel Modele dayalı Nitel bir araştırmadır. Araş̧ırma kapsamında literatür aranarak Aylan Kurdi ve ailesinin 2015 yılında çıktığı göç yolunda trajik biçimde hayatlarını kaybetmesinden yola çıkılarak çalışma Aylan Kurdi üzerinden işlenmiş, göç teması etrafında şekillenen sanat eserleri incelenmiş, yaşanan olayın plastik sanatlara yansımaları Ai Weiwei, Banksy, Pekka Jylhä gibi seçilmiş sanatçıların yapıtları özelinde değerlendirilmiştir. Bu çalışmada günümüzün salgını haline gelmiş ve tüm dünyayı etkisi altına almış şiddet olaylarından kaynaklanan ekonomik ve politik şartların kitleleri zorladığı göç olgusunun etkilediği plastik sanatlar alanındaki çalışmalar, 2015 yılında hayatını kaybeden Aylan Kurdi özelinde incelenmiş, bu çalışmalar yoluyla ortaya çıkan etkiler araştırmaya konu olmuştur.

\section{Bulgular}

\subsection{Günümüz Sanatında Göç}

Hayat-Sanat ikilisi tarih (Şengünalp, 2020, s. 822) boyunca birbirini etkilemiş ve özellikle sanat hayattan beslenip, günceli takip ederek mevcudiyetini korumaya devam etmiş̧ir. Sanatçıların yapıtları; bireysel deneyimlerinden, yaşadıkları coğrafyadan, içinde bulundukları toplumun gelenek ve göreneklerine kadar birçok farklı unsurdan etkilenerek şekillenmiştir. Temelde bir var olma çabası olarak göç, yeni yerlerde yerleşme ve kabul görme çabalarından ibaret değildir. Göçmen olmak, başka bir nedene ihtiyaç duymadan yabancılık, yalnızlık ve melankolik duygulara neden olabilmektedir (Adıgüzel, 2016, s. 154). Yapıtlarında göç teması etrafinda izler gördüğümüz sanatçıların çalışmaları da çoğunlukla bu deneyimlere bağlıdır. Devlet terörü, bireysel şiddet olayları, toplumsal bölünmeler, ekonomik ya da politik sebeplerle ortaya çıkan göç hareketleri genellikle gelişmiş ülkelere doğru yapılmış olmakla birlikte; yeni gidilen yurtlarda ortaya çıkan kimlik arayışı ve reddedilme durumları sanat yapıtlarına yansımışıı (Çeber, 2018). Sanatçıların göç ve göçmenlik üzerine deneyimleri galerilerden, sokaklara birçok mekânda dışa vurulmuştur ve özellikle günümüzün şiddet kaynaklı göç hareketleri sanata nesne olmaya devam etmektedir. Heykel, resim, sinema ve edebiyat gibi sanatın birçok alanında gördüğümüz göç temalı örneklerle sıklıkla karşılaşmaktayız. Bu eserlerin; göçmen kimliğine sahip olan sanatçıların yanında, göç ve göçmenliğe dikkat çekmek isteyen duyarlı sanatçılarca da yapıldığı görülmektedir. Kendileri göçmen oldukları için yaşadıkları deneyimleri sanat yapıtlarına yansıtan sanatçılara Sibel-Anny ÖZTÜRK kardeşler (Çeber, 2018) ve Shirin Neshat örnek gösterilirken, Banksy tarafından yapılan "Child in Venice" adlı çalışma da göç olgusunun nesneleştirildiği bir duyarlılık örneği olarak gösterilebilir. 


\section{Görsel 2}

Child in Venice

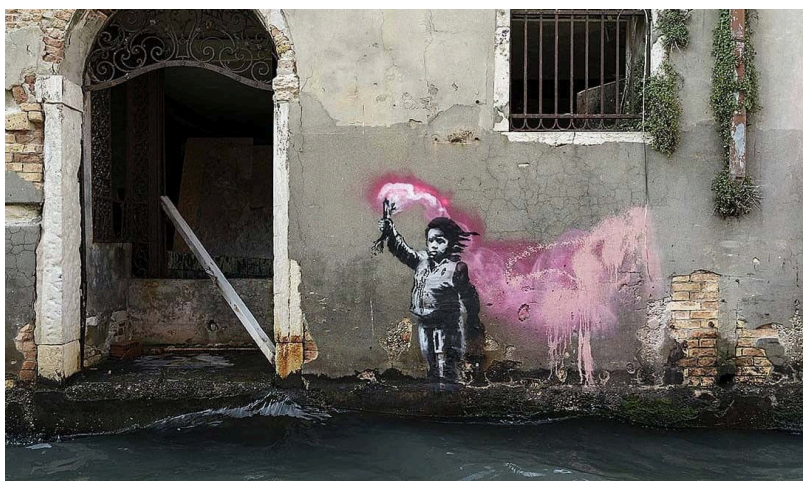

(Banksy, t.y.)

2019 yılı Venedik Bienali'nde sergilenen eserde, üzerinde basit bir can yeleği ve elinde neon bir meşale tutan göçmen çocuğun yardım bekler hali (Görsel 2) tasvir edilmiştir. Harabe haldeki bir yapının dış duvarına çizilmiş bu yapıtta seçilen neon mor renk dikkat çekicidir ve bilindiği üzere mor renk kraliyet rengi olarak kullanılmakla birlikte; Roma uygarlığında deniz canlılarından elde edildiği için çok kötü kokan bu boyayı üreten işçiler, aşağı görülen kölelerdir (Bond, 2017). Buradan hareketle eserden, göçmenlerin maruz kaldığı ya da maruz bırakıldığ 1 trajik olayların yansıması olmasının yanında; diğer taraftan özgürlüğün soyluların sahip olabileceği bir şey olduğu ya da eserin icra edildiği ülke de düşünülünce; mor 1şı üreten göçmen çocuğun hakir görüldüğü söylemleri çıkarılabilir mi?

Akdeniz'de yaşanan göç olaylarına vurgu yapan bir başka eser Fernando Sánchez Castillo tarafından yapılmış ve 2020 yılı eylül ayında De Balie'de sergilenmiştir (Görsel 3).

\section{Görsel 3}

Memorial (Mare Nostrum)

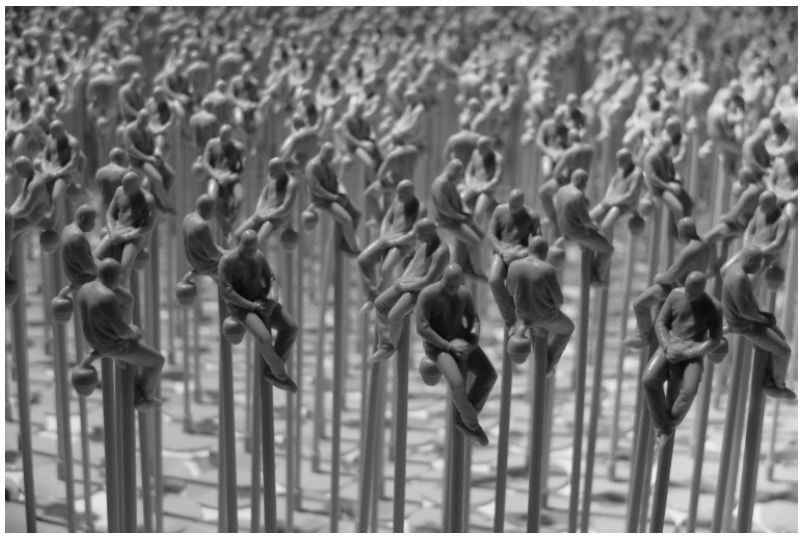

(Castillo, 2018).

Castillo tarafından yapılan eser, foto muhabir Santi Palacios tarafından çekilen bir fotoğrafın modellenmesi ile yapılmış ve 857 adet figür içermektedir. Afrika anakarasındaki İspanyol toprağı olan Melilla özerk bölgesinde yıllardır yasadışı sınır geçişleri yaşanmakta ve bu geçişler esnasında birçok trajedi meydana gelmektedir. Aynı zamanda uzun yıllardan beri Avrupa hayali ile yola çıkan göçmenlerin en sık kullandığı güzergâh olan Akdeniz, sayısız ölüme sahne olmuştur. 2019 yılında 19 Haziran'a kadar Akdeniz'de 857 kişi göç yolculuğunda hayatını kaybetmiştir ve buraya atıfla eser aynı figürün 857 tekrarından oluşmaktadır. Eserini "aynı hayalin daha iyi bir yaşam için tekrarlanmasının bir metaforu” olarak açıklayan sanatçı, Fas’ta sınırı geçmeye çalışırken fark edilince tepesine tırmandığı direğin üzerinden inmeyi reddeden genç bir göçmen imajı üzerinden, kökeninden ayrılma ve bilinçli bir yalnızlık tercihi alt metni ile göç ve etkilerine gönderme yapmaktadır.

\subsection{Aylan Kurdi ve Plastik Sanatlara Yansımaları}

2015 yılı eylül ayında ailesi ile birlikte göç yolculuğuna çıkan 3 yaşındaki Aylan Kurdi, Yunanistan'ın İstanköy sahiline çıkmak isterken botlarının batması sonucu annesi ve kardeşi ile birlikte hayatını kaybetmiş; cansız bedeni Bodrum sahilinde bulunmuştu. Yaşanan bu trajik son, tüm dünyada yüzlerce tepki ve söyleme kaynaklık etmiş; sanatın birçok dalında, özellikle plastik sanatlarda sayısız yansıma bulmuştur. Çin'li sanatçı Ai Weiwei duruma bir fotoğrafla tepki verirken, Finlandiya'lı sanatçı Pekka Jylhä realist bir heykelle yaklaşmıştır. 
Aylan Kurdi'nin kaybından kısa bir süre sonra Latifa Ahrar öncülüğünde 30 kişilik bir grup Fas'ın Rabat sahilinde kumsalda yüzüstü yatarak Aylan Kurdi ve daha önce İspanya sahillerine ulaşmaya çalışırken hayatlarını kaybeden Fas'lı mültecilerin anısına bir performans sergilemiştir. (Görsel 4) Farklı yaş aralıklarında aktivistlerden oluşan grubun üyeleri Aylan Kurdi gibi giyinmiş ve $20 \mathrm{dk}$ boyunca kumsalda uzanarak yaşanan trajik olayı canlandırmışlardır. Bu performans gösterisi daha sonra Ai Weiwei’nin çalışmasının da olduğu birden fazla benzer performansa ilham kaynağı olmuştur.

\section{Görsel 4}

Fas'lı Mülteciler Anısına Performans

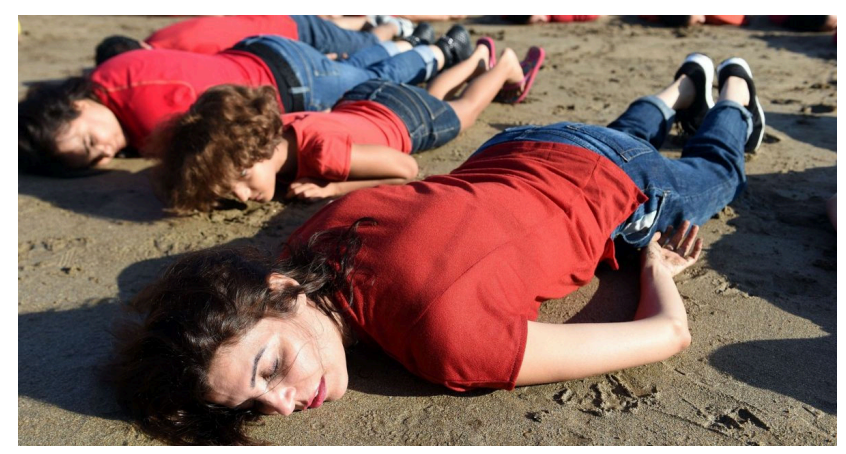

(Kurdi, 2015).

Latifa Ahrar'ın yönettiği performans ile Ai Weiwei’nin çalışması arasında görsel olarak benzerlik olsa da organize etmesine rağmen Latifa Ahrar performansa dâhil olmamıştır. Buradan hareketle Latifa Ahrar'ın; kişisel ekonomik ya da sosyal şartların, bireyin özgürlük düzeyini belirlediği mesajını vermeye çalıştığını düşündürmektedir.

Kendisi de bir mülteci olarak Amerika kıtasına göç etmek zorunda kalmış, muhalif kimliği ile bilinen Ai Weiwei uzun yıllardır dünya çapında özellikle Çin hükümetine karşı tutumu ve bu karşıtlığı yansıttığı çalışmaları ile tanınmaktadır. Sanatçı, son dönemlerde Hong Kong'da yapılan gösterilerde de aktif rol almıştır ve toplumu herhangi bir düzeyde ilgilendiren sorunları sanat vasıtası ile irdelemektedir. Ai Weiwei, Aylan bebek trajedisi karşısında da sessiz kalmamış, Midilli adasında bir sahilde çakıl taşlarının üzerine Aylan Kurdi'nin bulunduğu andaki hali ile uzanarak fotoğraflamış (Görsel 5) ve bu fotoğrafı Hindistan sanat fuarında sergilemiştir. Bu çalışma üzerine güncel sanat alanında yayın yapan E-Flux’ta Archey (2016) tarafından kaleme alınmış bir yazıda; Aylan bebek trajedisinin ifadesi için orta yaşlı, zengin ve güçlü bir adamın görüntüsünün ne kadar uygun olduğu tartışmaya açılmıştır. Aynı yazıda Ai Weiwei'nin bu fotoğrafla hem küresel boyutta sermaye edindiği hem de para kazandığ 1 iddia edilmektedir (Archey, 2016).

\section{Görsel 5}

Essential or Impudent? The Debate about Art and Refugees

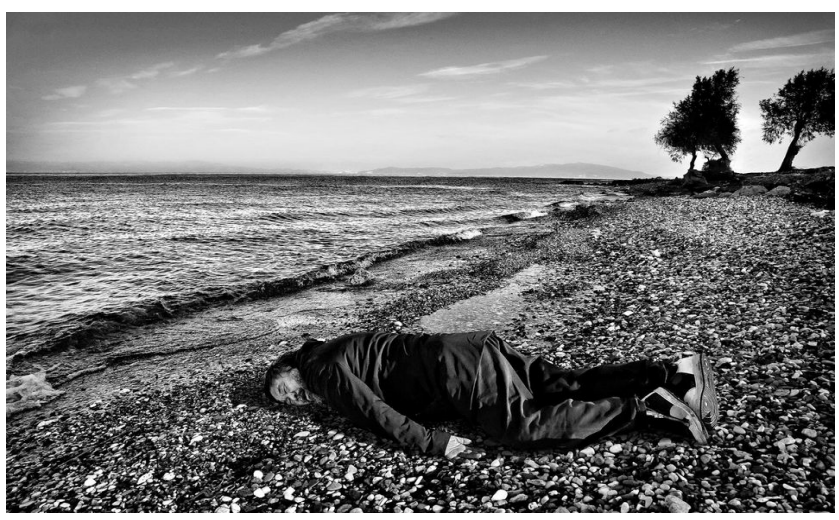

(Weiwei, 2016).

Öte yandan Columbia Üniversitesi'nde İran Araştırmaları ve Karşılaştırmalı Edebiyat alanında Hagop Kevorkian profesörü olan Hamid Dabashi tarafından kaleme alınarak, Al Jazeera' da yayınlanan yazıda Ai Weiwei için "bu sahte ölümle birlikte öldü, bu resim belki de en büyük intihar sanatı eseriydi" (Dabashi, 2020) ifadeleri kullanılmıştır. Aynı zamanda The Guardian yazarı Toby Fehily; Dabashi'nin sözlerine de atıf yaparak, "Ai Weiwei'nin politik bir fotoğraf çektirmek için ölü bir çocuk gibi poz vermesinden daha iyi yollar var” (Fehily, 2020) demiştir. Ai Weiwei daha önce de belirtildiği gibi muhalif kişiliği ile tanınmaktadır ancak Aylan Kurdi’nin kaybına dair yaptığı tartışmalı çalışmanın, küresel göç ve göçmenlerin içinde bulunduğu olumsuz koşulların iyileştirilmesi adına görünür bir katkı yapıp yapmadığı da tartışmaya açıktır. Latifa Ahrar'ın aksine Ai Weiwei, 
çalışmasında özne olarak kendi bedenini kullanmış ve Aylan Kurdi trajedisi ile empati düzeyinde bir iletişim kuran sanatçı, yaptığı birçok farklı çalışmada da göç ve göçmen konusunu irdelemiştir.

Diğer yandan Pekka Jylhä, Aylan bebeğin dünya gündemine oturan fotoğrafını, üçüncü boyuta taşımış ve realist bir heykel ile konuya değinmiştir. Sanatçının, dünya toplumunu göç ve sonuçlarına dair düşünmeye zorlayan "Deniz Onu Özgür Birakana Kadar" isimli eseri (Görsel 6) Helsinki Modern Sanatlar Galerisi'nde sergilenmektedir. Esere dair yazılanlardan biri Donna Roberts tarafından Finland Today'da kaleme alınmış ve Jylhä’nın çalışması ya da Aylan Kurdi ile ilgili diğer çalışmaların sembolik olduğunu ve bu on yılın insanlık felaketlerine etkili bir şekilde yanıt vermedeki yetersizliğimizi (Roberts, 2020) vurgulamaktadır. Bilgisayar destekli yontulan üç boyutlu Aylan Kurdi heykeli cam bir muhafazanın içerisinde (Görsel 6) korumaya alınmış gibi görünmektedir. Belki üç boyutlu bir nesne olarak heykelin plastik (Bulat, 2007, s. 73) dinamikleri ile çok yakın olmayabilir, ancak; Aylan Kurdi’nin bulunduğu andaki görüntüsünün bir imaj olarak korumaya alınarak, uyandırdığı etkiyi taze tutması bakımından sanatın etkili kullanım örneklerinden biri olabilir. Antik Yunan medeniyetinde deniz, bir daha asla görülmeyecek, her şeyin yok olabileceği bir yer olarak görülüyordu. Öyle ki; gemilerde istenmeyen kişiler, toplumdan dışlanan bireyler, toplum hafızasından silinmiş kişilerin heykelleri ve diğer tüm kirli görülen şeylerin atılabileceği bir çöplük gibiydi (Meck, 2011). Pekka Jylhä, dünya toplumunun sırtında bir yükmüş gibi kendilerinden kurtulma çabası ile denizde ölüme terkedilen göçmenlerin yaşadıklarını bu ikonik imaj ve camdan korumasına yansıtmıştır. Öte yandan Finlandiya gibi refah düzeyi oldukça yüksek ve özgürlükler ülkesi olarak bilinen ancak sadece yıllık kota ile mülteci kabul eden bir Avrupa birliği ülkesinde yapılmış olması nedeniyle dikkate değerdir. Aynı zamanda Finlandiya'nın 2017 yılında bastırdığ 15 euroluk madeni hatıra paralarının birinde (Görsel 7) Aylan Kurdi’nin fotoğrafını kullanarak üzerine "Küresel Adalet" yazması da (Finlandiya parasında, 2017) aynı bağlamda ironiktir.

\section{Görsel 6}

Until The Sea Shell Him Free

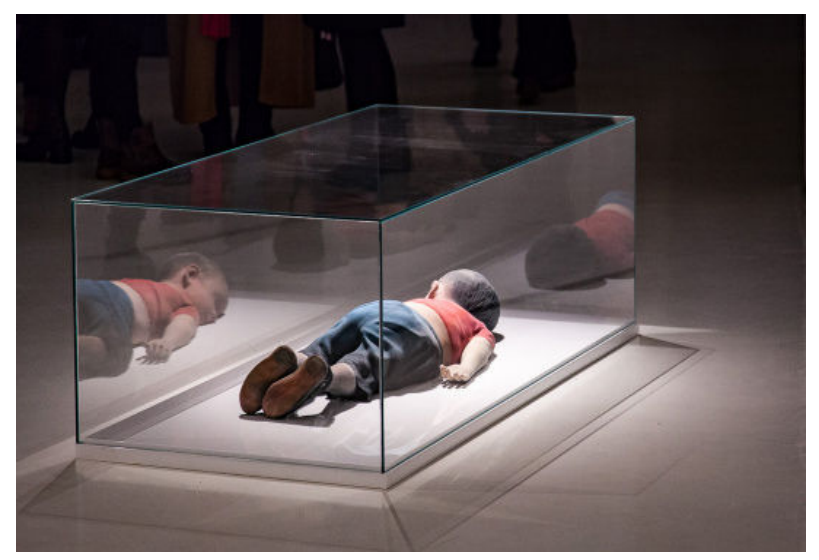

(Jylhä, 2016).

\section{Görsel 7}

Finlandiya'da Basılan Hatıra Madeni 5 Euro

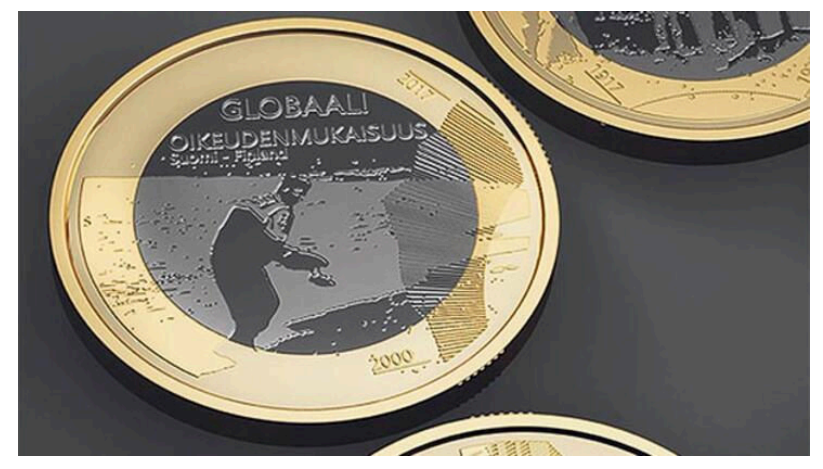

(Star Haber, 2017).

Aylan bebeğin kaybına dair yapılmış, belki de en önemli sanat eseri 2017 yılında Katoliklerin ruhani lideri Papa Francesco tarafından yaptırılarak Birleşmiş Milletler Gıda ve Tarım Örgütüne hediye edilen heykeldir (Görsel 8). İtalyan heykeltraş Luigi Prevedel tarafından 177x120x75 ölçülerinde yontulan (Rai, 2017) mermer heykelde yüzüstü yatan Aylan bebeğin başucunda ağlayan bir melek figürü (Putti) tasvir edilmiştir. Eski ve yeni ahitte sıkça söz edilen melekler, tanrının sözlerini insanlara ulaştırmanın yanında, korumasını ve cezasını da getirirler (Carr- 
Gomm, 2018). Bu bağlamda, Katolik dünyasının lideri olarak Papa Francesco bir elçi görevi görerek katoliklerin ortak duygularını Birleşmiş Milletler'e iletme misyonu üstlenmiş olduğu söylenebilir. Papa Francesco, aynı çerçevede, Birleşmiş Milletler Gıda ve Tarım Örgütü’nün Roma'daki merkezinde açılışı yapılan heykel ile, dünya ölçeğinde etkili ve ciddi finans kaynaklarına sahip Birleşmiş Milletler'in küresel göç ile ilgili yetersiz çabalarını vurgulamayı amaçladığını da düşündürmektedir.

\section{Görsel 8}

Aylan Kurdi Heykeli

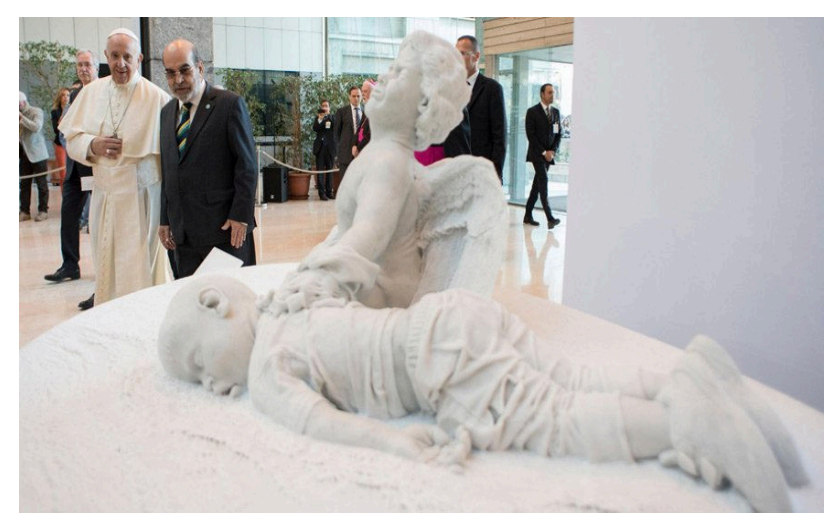

(Prevedel, 2017).

Aylan Kurdi ve göçmenlerin durumuna vurgu yapan çalışmalardan bir diğeri ise Frankfurt şehrinde yaklaşık 120 metrekarelik bir duvar resmidir (Görsel 9). Justus Becker ve Oğuz Şen tarafından yapılan çalışma, sanatçıların yalnızca suya yakın olmasının önemli olduğunu belirtmelerine rağmen, aynı zamanda Avrupa Merkez Bankası yakınlarında olması ile dikkat çekmektedir (Stern.de, 2020). Tüm dünyada bir sorun haline gelen göç ve etkilerini, kolektif hafızanın bir parçası haline getirmesi adına bu tür sanatsal çalışmalar son derece değerlidir. Aylan Kurdi'nin simge (Küçüköner, 2005, s. 77) haline geldiği trajedinin büyük boyutlarda resmedildiği eserin yarattığ1 etki aldığı tepkiler ile de ölçülebilir. Justus Becker ve Oğuz Şen tarafından yapılan çalışma uygulandıktan yaklaşık üç ay kadar sonra vandal bir saldırıya uğramış ve tahrip edilerek dilimizde "Sınırlar Hayatları Korur!" anlamında “'Grenzen retten leben!” yazılmıştır (Šimić, 2018) (Görsel 9).

\section{Görsel 9}

Aylan Kurdi Duvar Resmi

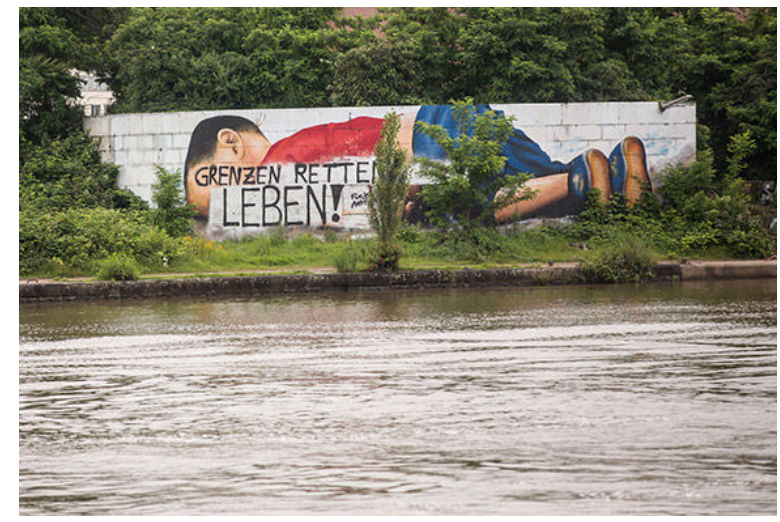

(Becker ve Şen, t.y.).

\section{Sonuç}

2015 Aralık ayında yayınlanan bir rapora göre Aylan Kurdi'nin bulunduğu anın fotoğrafı iki saat içinde 100 farklı ülkede yarım milyonun üzerinde twitter kullanıcısına ulaşmış (Vis \& Goriunova, 2015) ve geniş çaplı bir etki yaratmıştır. Fotoğrafın ilk iki saat içinde aldığı etkileşim ilk 24 saat içinde aldığı etkileşimin \%3'ne tekabül etmektedir ve görsel 10'da ilk üç saat içindeki yayılımı görülebilir (Vis \& Goriunova, 2015). Dünya çapında etkiler yaratan olay, çok büyük oranda göçmen yanlısı söylemlere kaynaklık etmişken, aynı zamanda kısa süreli de olsa bazı Avrupa ülkelerinin göçmen kabul sayılarını arttırdığı gözlemlenmiştir. Öte yandan charli hebdo gibi bazı yayın organlarında da bir takım küçük düşürücü, aşağılayıcı hatta çirkin denebilecek söylemlerin ortaya çıkmasına da sebep olmuş, etiğe aykırı olacağı kanısıyla görseller bu çalışmaya dâhil edilmemiştir. 


\section{Görsel 10}

Aylan Kurdi Fotoğrafinın Twitter'da İlk Üç Saat İçinde Aldı̆̆ Etkileşim

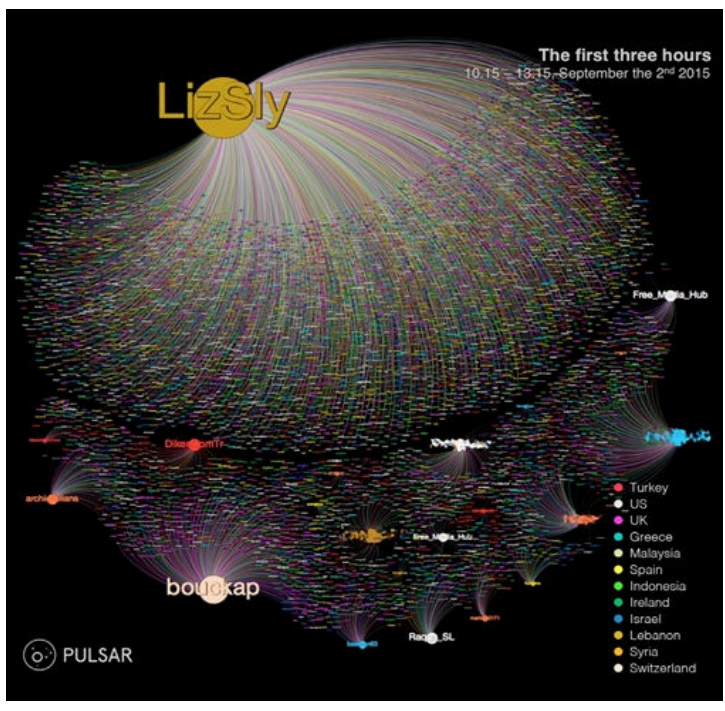

(D’Orazio, 2016).

Günümüzde göç, küresel bir sorun haline gelmiştir ve birçok alanda toplumların yaşam şekillerini etkilemektedir. Göçün yarattığı etkiler; siyasal, ekonomik, kültürel ve sosyal alanlarda olduğu gibi sanat alanında da görülmektedir. Göç hareketleri sırasında ve sonucunda yaşananlar farklı sanat dallarında sayısız örneklere kaynaklık etmiştir. Özellikle toplumları etkileyen göç hareketleri ve dünya çapında büyük etki yaratan trajik olaylar, her alanda olduğu gibi sanat alanında da daha fazla etki yaratmaktadır. Gelişen teknoloji ve iletişim altyapısının güçlenmesi ile yaşanan herhangi bir durum bir anda dünya gündemine oturabilmektedir. 2015 yılında Bodrum sahilinde yaşanan ve Aylan Kurdi'nin kaybı ile sonuçlanan olay, saatler içinde binlerce etkileşim almasıyla bu duruma örnek olarak gösterilebilir. DHA muhabiri Nilüfer Çelik tarafından çekilen fotoğraftan sonra, çocuğun yaşadığı dramatik son NATO, BM gibi uluslararası kurumların toplantılarına konu olmuş, birçok ülkenin göç politikasını değiştirmesine sebep olmuştur. Aylan Kurdi'nin kaybı bu etkilerin dışında sanat alanında da yansımalar bulmuş; sinema, edebiyat gibi birçok disiplinde özne olarak kullanılmış, göç ve göçmenlik kavramları imgelenmiştir. Göç ve sonuçları etrafında şekillenerek izleyici karşısına çıkarılan diğer sanat eserlerinde olduğu gibi, sanatçıların bireysel olarak bu konuda sergiledikleri tavır ve dünyaca ünlü birçok sanatçının yapıtlarına konu olan göç kavramı, Aylan Kurdi'nin son görüntüsü ile özdeşleşerek dikkat çekmiştir. Öyle ki; Aylan Kurdi’nin kaybına atfen yapılan sanat eserleri Papalık ve Birleşmiş Milletler düzeyinde söylemler üretmiştir. Ai Weiwei gibi dünyaca ünlü sanatçıların yapıtlarına konu olan, birçok farklı ülkede farklı anlayışta yapılan sanat eseri ile toplumların belleğinde yer edinen kayıp, göç yolunda yaşanan trajik olaylara dikkat çekmiştir. Aylan Kurdi'nin kaybından sonra dünya toplumunun duyarlılığı zirveye ulaşmış, sanatçıların da destek olduğu kurtarma operasyonları yürütülmüştür. Örneğin Banksy tarafından satın alınan askeri bir bot akdenizde mahsur kalan göçmenleri kurtarmak için gizlice yola çıkmış ve yüzlerce göçmeni kurtarmıştır. Sadece beş yıl gibi kısa bir zaman önce yaşanmış olmasına rağmen hakkında yapılan onlarca sanat eseri ve olayı irdeleyen sanatçıların tanınırlığı plastik sanatlara etkisinin boyutlarını gözler önüne sermektedir. 


\section{Kaynakça}

Adıgüzel, Y. (2016). Göç sosyolojisi (1 b.). Nobel Akademik Yayıncılık.

Aksoy, Z. (2012). Uluslararası göç ve kültürlerarası iletişim. Uluslararası Sosyal Araştırmalar Dergisi, 5(20), 292-303. https://www.sosyalarastirmalar.com/cilt5/cilt5sayi20 pdf/5 sosyoloji felsefe/\%20aksoy zeynep. $\underline{\mathrm{pdf}}$

Archey, K. (2016, Şubat). For photo op, Ai Weiwei poses as dead refugee toddler from iconic image. E-Flux Conversations. https://conversations.e-flux.com/t/for-photo-op-ai-weiwei-poses-as-dead-refugee-toddlerfrom -iconic-image/3169

Banksy. (t.y.). Child in Venice [Fotoğraf]. Austin Museum of Popular Culture, Austin, Texas, United States. https://www.highsnobiety.com/p/banksy-migrant-child-venice-mural/

Becker, J., \& Şen, O. (t.y.). Aylan Kurdi duvar resmi [Grafiti]. https:/www.nrz.de/panorama/graffiti-des-totenfluechtlingsjungen-aylan-kurdi-zerstoert-id11940674.html

Bond, S. E. (2017, Ekim). The hidden labor behind the luxurious colors of purple and indigo. Hyperallergic. https:/hyperallergic.com/406979/the-hidden-labor-behind-the-luxurious-colors-of-purple-and-indigo/

Bulat, M. (2010). Form ve kompozisyon. Sanat Dergisi, O(12), 73-78. https://dergipark.org.tr/tr/download/articlefile/28932

Carr-Gomm, S. (2018). Sanat- sanatın gizli dili. İnkılap Kitabevi.

Castillo, F. S. (2018). Memorial [Heykel]. CentroCentro, Madrid, Spain. https://fundacionnmac.org/es/2018/12/ 18/fernando-sanchez-castillo-en-madrid/

Çalışkan, S. (2018). Çağdaş sanat eserlerine göç olgusu perspektifiyle bir bakış. İdil, 7(41), 39-45. https://doi.org/ 10.7816/idil-07-41-06

Çeber, T. (2018). Plastik sanatlardaki üretimlerde ele alınış biçimiyle göç olgusu. Sanat ve Tasarım Dergisi, 22, 97-109. https://dergipark.org.tr/tr/download/article-file/609714

D’Orazio, F. (2016). Aylan Kurdi Fotoğrafinın Twitter'da ilk üç saat içinde aldı̆̆ı etkileşim [Fotoğraf]. https://www.pulsarplatform.com/blog/2016/journey-of-an-image-from-a-beach-in-bodrum-to-twenty-million -screens-across-the-world/

Dabashi, H. (2016, 4 Şubat). A portrait of the artist as a dead boy. Aljazeera. https://www.aljazeera.com/opinions/ 2016/2/4/a-portrait-of-the-artist-as-a-dead-boy

Dedert, A. (2016, 10 Mart). Mainufer in Frankfurt: Riesiges mahnmal für toten flüchtlingsjungen Aylan. Stern. https:/www.stern.de/kultur/kunst/aylan-kurdi--riesiges-mahnmal-in-frankfurt-fuer-toten-fluechtlingsjungen6741916.html

Fehily, T. (2016, 6 Şubat). There are better ways for Ai Weiwei to take a political stand than posing as a drowned infant. Theguardian. https:/www.theguardian.com/artanddesign/2016/feb/06/there-are-better-ways-for-aiweiwei-to-take-a-political-stand-than-posing-as-a-drowned-infant

Finlandiya parasında Aylan'ın resmi. (2017, 5 Mayıs). Milliyet. https:/www.milliyet.com.tr/dunya/finlandiyaparasinda-aylan-in-resmi-2444600

Jylhä, P. (2016). Until the sea shell him free [Heykel]. Helsinki Contemporary Gallery, Helsinki, Finland. https://ollilaasanen.wordpress.com/2016/03/05/one-misfortune-at-a-time/

Kınık, K. (2012). Göç, sürgün ve iltica. Hayat Sağllk Dergisi, 36-39. http://keremkinik.com/wpcontent/uploads/2017/10/G\%C3\%B6\%C3\%A7-S\%C3\%BCrg\%C3\%BCn-ve-\%C4\%B0ltica.pdf

Kurdi, A. (2015). Fas'll mülteciler anısına performans [Fotoğraf]. https://www.dailymail.co.uk/news/article3227703/Thirty-people-recreate-death-Alyan-Kurdi-laying sand-Moroccan-beach-dressed-clothes-drownedSyrian-boy.html

Küçüköner, M. (2005). Sanatta imge, simge ve gösterge ilişkilerine bir bakış. Sanat Dergisi, 0(7), 76-82. https://dergipark.org.tr/tr/download/article-file/28857

Lawrence, J. (1941). One-way ticket: Jacob Lawrence's migration series [Resim]. The Museum of Modern Art, New York, NY, United States. https://www.moma.org/interactives/exhibitions/2015/onewayticket/panel/40/

Meck, J. (2011). The Sea: A cultural history. Reaktion Books. 
Prevedel, L. (2017). Aylan Kurdi heykeli [Heykel]. https://www.hurriyet.com.tr/dunya/papadan-bmye-alan-kurdiheykeli-40612818

Rai. (2017, 16 Ekim). Papa Francesco dona statua dedicata al piccolo Aylan morto sulle coste turche. RaiNews. http://www.rainews.it/dl/rainews/media/Papa-Francesco-dona-statua-dedicato-al-piccolo-Aylan-morto-sullecoste-turche-5f3c8a2b-4173-478e-a5d4-6fb672198496.html

Roberts, D. (2016, 10 Mart). The drowned refugee Aylan Kurdi and other horrors on display at Helsinki contemporary. Finlandtoday. https://finlandtoday.fi/the-drowned-refugee-aylan-and-other-horrors-on-display -at-helsinki-contemporary/

Šimić, L. (2018). My sea: On the waves of poetics and politics. Performance Research, 23, 74-78. https://doi.org/10.1080/13528165.2018.1518613

Star Haber. (2017). Finlandiya'da basılan hatıra madeni 5 Euro [Fotoğraf]. https://www.star.com.tr/dunya/ paranin-uzerinde-o-fotograf-yer-alacak-haber-1214294/

Şengünalp, C. (2020). Heykelin politik bir imgeye dönüşümü: Harburg anıtı örneği. Uluslararası Kültürel ve Sosyal Araştırmalar Dergisi, 6(2), 816-826. https://doi.org/10.46442/intjcss.837583

Türk Dil Kurumu. (1998). Göç. Türk Dil Kurumu Türkçe Sözlük (Cilt 1) içinde.

Vis, F., \& Goriunova, O. (2015). The iconic ımage on social media: A rapid research response to the death of Aylan Kurdi. Visual Social Media Lab. https://www.scribd.com/document/293236608/Visual-Social-MediaLab-The-Iconic-Image-on-Social-Media-a-rapid-research-response-to-the-death-of-Aylan-Kurdi\#from embe $\underline{\mathrm{d}}$

Weiwei, A. (2016). Essential or impudent? The debate about art and refugees [Fotoğraf]. https://www.dw.com/ en/essential-or-impudent-the-debate-about-art-and-refugees/a-39177781

Yedikardeş, C. (2020). Erzurum ili özelinde 3-6 yaş aralığındaki okul öncesi gruplarla temel becerileri geliştirmeye yönelik kil uygulamaları. Sanat Ë̆itimi Dergisi, 8(1), 22-31. https://www.sanategitimidergisi.com/makale/ pdf/1592310037.pdf 